CLINICAL STUDY

\title{
Effects of oral and transdermal estrogen therapies on circulating cytokines and chemokines in postmenopausal women with hysterectomy
}

\author{
Toshiyuki Yasui ${ }^{1}$, Ayako Saijo ${ }^{1}$, Hirokazu Uemura ${ }^{2}$, Toshiya Matsuzaki ${ }^{1}$, Naoko Tsuchiya ${ }^{3}$, \\ Mitsutoshi Yuzurihara $^{3}$, Yoshio Kase ${ }^{3}$ and Minoru Irahara ${ }^{1}$ \\ ${ }^{1}$ Departments of Obstetrics and Gynecology and ${ }^{2}$ Preventive Medicine, Course of Human Development, Human Development and Health Science, Institute of \\ Health Biosciences, The University of Tokushima Graduate School, 3-18-15 Kuramoto, Tokushima 770-8503, Japan and ${ }^{3}$ Pharmacology Research \\ Department, Tsumura Central Research Institute, 3-18-15 Kuramoto, Tokushima 770-8503, Japan \\ (Correspondence should be addressed to T Yasui; Email: yasui@clin.med.tokushima-u.ac.jp)
}

\begin{abstract}
Objective: The aim of the present study was to determine the different effects of oral estrogen therapy (ET) and transdermal ET on changes in circulating levels of cytokines and chemokines in relationship to changes in markers of inflammation in postmenopausal women with hysterectomy.

Methods: Fifty-five postmenopausal women with hysterectomy were randomly assigned in open, parallel-group fashion to an oral ET group and a transdermal ET group. Serum levels of cytokines and chemokines were simultaneously measured using a multiplexed human cytokine assay. Serum concentrations of high-sensitive C-reactive protein, soluble vascular cell adhesion molecule-1, soluble intercellular adhesion molecule-1, and E-selectin were measured as vascular inflammation markers.

Results: Both oral ET and transdermal ET significantly decreased serum interleukin (IL)-7 concentrations at 12 months $(P=0.020$ and $P=0.015$ respectively). Transdermal ET decreased serum concentrations of IL-8, monocyte chemoattractant protein (MCP)-1, and macrophage inflammatory protein (MIP)-1 $\beta(P=0.05, P=0.019$, and $P=0.029)$, but oral ET increased IL-8 level $(P=0.025)$. There were significant differences in percentage changes in IL- 8 and MIP-1 $\beta$ between the oral and transdermal ET groups. Oral ET significantly decreased E-selectin level after 12 months.

Conclusion: Transdermal ET reduces circulating levels of IL-8, MCP-1, and MIP-1 $\beta$, while both oral ET and transdermal ET reduce circulating level of IL-7.
\end{abstract}

European Journal of Endocrinology 161 267-273

\section{Introduction}

The effects of hormone therapy (HT) on C-reactive protein (CRP) and cell adhesion molecules associated with development of atherosclerosis have been shown to be different depending on the route of estrogen administration (1-5). Cytokines and chemokines, such as interleukin (IL)-6, IL-1 $\beta$, tumor necrosis factor- $\alpha$, IL-10, and monocyte chemoattractant protein (MCP)-1, related to the development of atherosclerosis have been reported to be changed by HT (1-8).

Recently, other cytokines and chemokines as factors involved in the development of atherosclerosis have been investigated. IL-7 has been reported to be involved in the first step of adhesion of leukocytes to endothelial cells $(9,10)$, and its receptor has been reported to be present in human microvascular endothelial cells (11). Circulating IL-8 level has been shown to be high in patients with atherosclerosis (12). Macrophage inflammatory protein (MIP)-1 $\beta$ has been reported to be expressed by $\mathrm{T}$ cells in advanced atherosclerotic lesions (13). The effects of HT on these cytokines and chemokines and the differences in these cytokines and chemokines between women receiving oral HT and women receiving transdermal HT have not been demonstrated.

In addition, results of studies regarding the action of progestogen in an HT regimen on vascular inflammation have been inconsistent $(14,15)$. The effects of estrogen therapy (ET) and estrogen-progestogen therapy on cytokines and chemokines may be different.

The aim of the present study was to determine the different effects of oral ET and transdermal ET on changes in circulating levels of cytokines and chemokines in relationship to changes in markers of inflammation in postmenopausal women who have undergone hysterectomy. 


\section{Subjects and methods}

\section{Subjects}

The subjects of this study were recruited from patients visiting the outpatient clinic of the Department of Obstetrics and Gynecology, Tokushima University Hospital with complaints of menopausal symptoms. Fifty-five postmenopausal women who had undergone hysterectomy were enrolled in this study between January 2006 and December 2007. All subjects were premenopausal women at the time of hysterectomy. Postmenopausal status was confirmed by FSH concentration $\geq 40 \mathrm{mIU} / \mathrm{ml}$ and estradiol $\left(\mathrm{E}_{2}\right)$ concentration $\leq 20 \mathrm{pg} / \mathrm{ml}$.

Before recruitment in the study, patients underwent gynecological and biochemical examinations that included bimanual examination and transvaginal ultrasonography. Reviews of medical histories and the results of physical examinations and blood chemistry tests showed that all of the women were in good health. Exclusion criteria in the study were a history of any cardiovascular disease, hormonedependent malignancy or breast cancer, venous thromboembolic disease, diabetes mellitus, renal dysfunction, liver disease, hypertension, and use of lipid-lowering drugs. Women who had received HT in the past were not included in the study. None of the subjects had taken any medication known to influence the immune system for at least 1 year. Subjects suspected of having infectious diseases, inflammatory disorders, malignancy or autoimmune diseases, of being undernourished, or of abusing alcohol or drugs were excluded according to the SENIEUR protocol (16). The SENIEUR protocol provides the structural basis for analyses of aging in a well-defined healthy population and strict criteria for human immunogerontologic studies.

Fifty-five postmenopausal women who had undergone hysterectomy were randomly assigned to one of two groups by registration number of the hospital for the duration of the 12-month study: a continuous oralconjugated equine estrogen (CEE) therapy group $(0.625 \mathrm{mg} /$ day; $n=27)$ and a continuous transdermal $\mathrm{E}_{2}$ therapy group ( $50 \mu \mathrm{g}$ of $\mathrm{E}_{2}$ released in $24 \mathrm{~h}$ by a transdermal patch; $n=28$ ). The patients who visited our hospital on odd-numbered days were treated with oral CEE, and those who visited our hospital on evennumbered days were treated with transdermal $\mathrm{E}_{2}$. We assessed compliance by pill count and sheet count. In addition, we assessed the status of hot flashes. Venous blood samples were drawn into tubes between 0800 and $1000 \mathrm{~h}$ after 12 -h fasting before and at 12 months after commencement. Samples obtained were frozen at $-70{ }^{\circ} \mathrm{C}$ until used for analysis. Informed consent for participation in this study was obtained from each woman. The Ethics Committee of Tokushima University Hospital approved the study.
Serum $\mathrm{E}_{2}$ concentration was measured by a two-site immunoenzymometric assay using a commercially available kit (TOSOH Co., Tokyo, Japan). The intraand inter-assay coefficients of variation (CV) were 4-9 and $6-9 \%$ respectively. Serum FSH concentration was measured by an IRMA using a commercially available kit (TFB Co., Tokyo, Japan). The intra- and inter-assay CV were $3-4$ and $3-4 \%$ respectively.

The concentration of high-sensitive C-reactive protein (hsCRP) was measured by the Behring Latex-Enhanced CRP assay using a Behring Nephelometer Analyzer System (Dade Behring, Tokyo, Japan). Assays for soluble vascular cell adhesion molecule (sVCAM)-1, soluble intercellular adhesion molecule (sICAM)-1, and E selectin were carried out using ELISA kits (R\&D Systems, Minneapolis, MN, USA). The intra- and interassay CV were $0.9-1.7$ and $2.3-3.0 \%$ for CRP, $2.2-2.8$ and $6.5-9.5 \%$ for sVCAM, $6.5-7.9$ and $7.6-11.6 \%$ for sICAM, and 3.3-4.9 and $3.1-4.8 \%$ for E-selectin respectively. All assays were carried out in duplicate.

Serum concentrations of seven cytokines and chemokines (IL-5, IL-6, IL-7, IL-8, IL-10, MIP-1 $\beta$, and MCP-1) were measured using a Bio-Plex human cytokine assay kit (Bio-Rad Laboratories) as previously reported (17). Assays of cytokines and chemokines were carried out in duplicate using a Bio-Plex human cytokine assay kit. The intra- and inter-assay CVs were 2.0-10.0 and $3.5-16.1 \%$ respectively. Intra-assay CV was calculated from eight samples within a single plate. Inter-assay CV was calculated from five samples each from three plates. The sensitivity levels were $1.1 \mathrm{pg} / \mathrm{ml}$ for IL- 6 and MIP- $1 \beta, 0.5 \mathrm{pg} / \mathrm{ml}$ for IL-7 and IL- $8,0.8 \mathrm{pg} / \mathrm{ml}$ for IL-5, $0.9 \mathrm{pg} / \mathrm{ml}$ for IL-10, and $6.7 \mathrm{pg} / \mathrm{ml}$ for MCP-1.

\section{Statistical analysis}

Based on the results of a previous study (3), sample size was estimated to detect at least $20 \%$ change in levels of cytokines and chemokines after administration with $80 \%$ power at the 0.05 level of significance. We defined the values below the detection limit as half of the detection limit in further analyses. Differences between oral and transdermal ET groups in subject characteristics and baseline serum concentrations of hormones were analyzed by an unpaired $t$-test, and values are presented as means \pm s.D.s. Baseline serum levels of inflammatory markers, cytokines, and chemokines, which were not normally distributed, are presented as medians with 25 th and 75 th percentile ranges, and significance of those values was evaluated by the non-parametric Wilcoxon rank-sum test. Baseline and follow-up levels of inflammatory markers and cytokines were compared across the same therapy by the non-parametric Wilcoxon signed-rank test. The percentage changes from baseline levels in the oral and transdermal ET groups were compared by the nonparametric Wilcoxon rank-sum test. The relationship among continuous variables was determined by using 
Spearman's rank-order analysis. $P$ values $<0.05$ were considered to be statistically significant. The SAS software package (version 8.2, SAS Institute Inc., Cary, NC, USA) was used for both data management and analysis.

\section{Results}

\section{General characteristics}

Out of the 55 women, 53 who originally enrolled completed the 12-month study. Two women who received transdermal $E_{2}$ dropped out of the study at 2 months because of skin irritation. Baseline characteristics according to assignment are presented in Table 1. There were no significant differences between the two groups in age, body mass index (BMI), and serum concentrations of FSH and $\mathrm{E}_{2}$.

\section{Changes in serum concentrations of cytokines and chemokines}

Baseline levels of cytokines and chemokines were not significantly different between the two groups. As can be seen in Table 2 and Fig. 1, serum IL-7 concentrations in the oral and transdermal ET groups were decreased significantly at 12 months $(P=0.020$ and $P=0.015$ respectively). There was no significant difference in percentage changes in $\mathrm{IL}-7$ between the oral and transdermal ET groups. Serum IL-8 level at 12 months was significantly $(P=0.025)$ increased in the oral ET group, but was decreased $(P=0.05)$ in the transdermal ET group (Table 2 and Fig. 1). Serum MIP- $1 \beta$ level at 12 months was significantly $(P=0.029)$ decreased in the transdermal ET group, but tended to be increased $(P=0.069)$ in the oral ET group. There were significant differences $(P=0.008$ and $P=0.017$ respectively) in percentage changes in IL- 8 and MIP- $1 \beta$ between the oral and transdermal groups. Serum MCP-1 level at 12 months was significantly $(P=0.019)$ decreased in the transdermal ET group, but there was no significant change in the oral ET group. IL-6 level tended to increase $(P=0.052)$ in the oral ET group, but remained unchanged throughout the study in the transdermal ET group.

Table 1 Baseline characteristics of postmenopausal women receiving oral and transdermal estrogen therapies.

\begin{tabular}{lrcc}
\hline & Oral & Transdermal & $P$ value \\
\hline Number & \multicolumn{1}{c}{27} & 28 & \\
Age (years) & $50.8(5.0)$ & $50.0(6.5)$ & 0.606 \\
Years since hysterectomy & $5.4(3.5)$ & $4.3(3.7)$ & 0.224 \\
BMl $\left(\mathrm{kg} / \mathrm{m}^{2}\right)$ & $22.0(2.7)$ & $22.9(3.4)$ & 0.243 \\
FSH $(\mathrm{mlU} / \mathrm{ml})$ & $103.3(48.1)$ & $90.2(32.9)$ & 0.244 \\
Estradiol $(\mathrm{pg} / \mathrm{ml})$ & $13.4(4.0)$ & $14.8(5.0)$ & 0.317 \\
\hline
\end{tabular}

Values are mean \pm (s.D.s). BMI, body mass index. FSH, follicle-stimulating hormone 

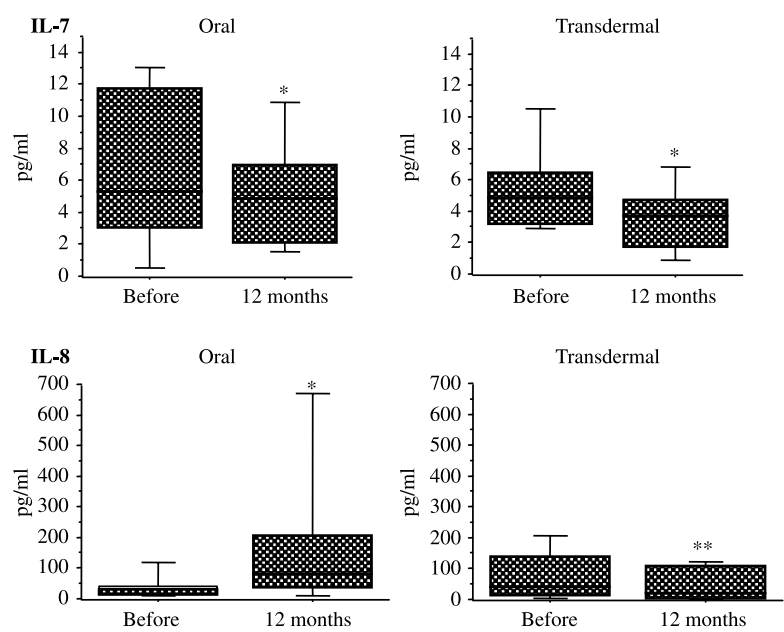

Figure 1 Box and whisker plots showing the values of IL-7 and IL-8 before and after 12 months in women receiving oral and transdermal estrogen therapies. Small horizontal bars represent the 10th-90th percentile range, and boxes indicate the 25th-75th percentile range. The horizontal line in each box corresponds to the median. ${ }^{*} P<0.05$ versus before treatment, ${ }^{\star \star} P=0.05$ versus before treatment.

\section{Association of $E_{2}$ concentration with concentrations of cytokines and chemokines}

Mean levels of $E_{2}$ at 12 months after the start of treatment in the oral and transdermal ET groups were $57.7 \pm 24.5 \mathrm{pg} / \mathrm{ml}(\mathrm{mean} \pm$ s.D. $)$ and $53.8 \pm 26.1 \mathrm{pg} / \mathrm{ml}$ respectively. These $\mathrm{E}_{2}$ levels in both groups were not correlated with levels of cytokines and chemokines.

\section{Changes in serum concentrations of inflammatory markers}

E-selectin level was decreased significantly at 12 months $(P=0.029)$ in the oral ET group (Table 3$)$. Serum show significant changes in both groups.

\section{Association of IL-8 with status of hot flashes}

Hot flashes were observed in 15 women in the oral ET group and 17 women in the transdermal group before treatment. As shown in Table 4, median serum IL-8 levels in women with hot flashes were significantly higher than those in women without hot flashes in both the oral ET and transdermal ET groups. In the transdermal ET group, serum IL-8 level was significantly $(P=0.015)$ decreased at 12 months after treatment in women with hot flashes, while there was no significant difference between median IL-8 levels before and at 12 months after treatment in women without hot flashes. In the oral ET group, there was no significant difference between median IL-8 levels before concentrations of hsCRP, sICAM, and sVCAM did not

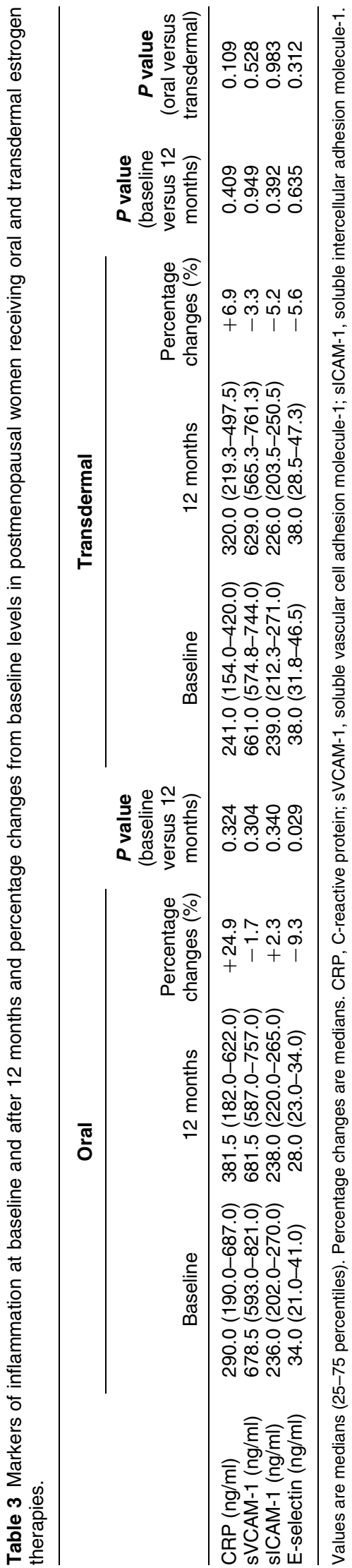

www.eje-online.org 
Table 4 IL-8 levels at baseline and after 12 months in postmenopausal women with and without hot flashes receiving oral and transdermal estrogen therapies.

\begin{tabular}{|c|c|c|c|c|c|c|}
\hline & \multicolumn{2}{|c|}{ Oral } & \multirow{2}{*}{$\begin{array}{c}\boldsymbol{P} \text { value } \\
\text { (baseline versus } \\
12 \text { months) }\end{array}$} & \multicolumn{2}{|c|}{ Transdermal } & \multirow{2}{*}{$\begin{array}{c}\boldsymbol{P} \text { value } \\
\text { (baseline versus } \\
12 \text { months) }\end{array}$} \\
\hline & Baseline & 12 months & & Baseline & 12 months & \\
\hline $\begin{array}{l}\text { Women with hot } \\
\text { flashes }\end{array}$ & $100.2(33.1-121.0)$ & $69.1(38.0-107.7)$ & 0.546 & $130.8(26.8-158.3)$ & $18.0(9.6-113.3)$ & 0.015 \\
\hline $\begin{array}{l}\text { Women without } \\
\text { hot flashes }\end{array}$ & $16.5(13.0-22.4)$ & $120.8(76.7-302.0)$ & 0.011 & $17.3(7.7-56.7)$ & $33.0(6.8-103.9)$ & 0.235 \\
\hline
\end{tabular}

Values are medians (25-75 percentiles).

and at 12 months after treatment in women with hot flashes, and serum IL-8 level in women without hot flashes was significantly increased at 12 months after treatment.

\section{Discussion}

Both treatments with oral estrogen and transdermal estrogen decreased serum IL-7 levels after 12 months of therapy. IL-7 is a pleiotropic non-redundant cytokine for the development and homeostatic maintenance of $\mathrm{T}$ and $\mathrm{B}$ lymphocytes, and its receptor has been reported to be present in human microvascular endothelial cells (11). It has been demonstrated that IL-7 induced the binding of unstimulated $\mathrm{T}$ cells to vascular cell adhesion molecules (9), and that IL-7 stimulated the expression of adhesion molecules on the cell surface in a murine endothelial cell line (10). Recently, we have showed that circulating IL-7 level was reduced by administration of a selective estrogen receptor modulator (18). Therefore, estrogen may inhibit the induction of adhesion molecules due to suppression of the action of IL-7 via the estrogen receptor. Among cell adhesion molecules, we showed that oral ET significantly reduced E-selectin level, but that E-selectin level in the transdermal ET group did not change. Our results regarding the change in E-selectin caused by oral ET are consistent with the results of previous studies $(19,20)$. The inhibitory effect of oral estrogen on the secretion of E-selectin through IL-7 might be stronger than that of transdermal estrogen.

In the present study, we confirmed that serum IL-8 concentration in women with hot flashes was higher than that in women without hot flashes as shown in our previous study (21). In addition, we showed that oral ET increased IL-8 level, but that transdermal ET decreased IL-8 level. In our previous study, we found that elevated level of cytokine-induced neutrophil chemoattractant, a member of the IL-8 family, was reduced by $\mathrm{E}_{2}$ and that elevated skin temperature in ovariectomized rats was reduced by treatment with injection of a luteinizing hormone-releasing hormone agonist (22). This result observed in rats was also observed in women with hot flashes in the transdermal group in the present study. ET may reduce IL-8 level in order to modulate the homeostasis of body temperature in postmenopausal women. However, IL-8 level did not change significantly in women with hot flashes in the oral ET group. Estrogen administered orally is absorbed in the gut and moves to the liver. IL- 8 has been reported to be produced in liver and bile ductular epithelial cells $(23,24)$. Therefore, production of IL-8 may have been increased due to action on the liver and bile duct through a first-pass hepatic effect in the oral ET group. On the other hand, it has been reported that IL-8 was induced by low shear stress in endothelial cells (25), and that the amount of IL-8 produced in visceral adipose tissue was greater than that in s.c. adipose tissue (26). The increase in IL-8 in the oral ET group may reflect the production from vascular endothelial cells and adipose tissue.

Results of previous studies showed that IL- 6 level was not changed significantly $(4,27)$ and was increased $(6,20)$ by oral ET. In the present study, oral ET tended to increase IL-6 level, but IL- 6 in the transdermal ET group did not change. It has been reported that IL-6 is synthesized by Kupffer cells in the liver (28). Therefore, increase in IL- 6 by oral ET might be due to first-pass hepatic metabolism. On the other hand, it has been reported that production of IL-6 in blood mononuclear cells and IL- 6 level in serum were decreased by transdermal ET $(29,30)$. IL-6 is involved in not only inflammation but also regulation of endocrine and metabolic functions, and it is produced and released from the adrenal gland by stimulation with corticotropin (31) as well as monocytes, T lymphocytes, endothelial cells, and adipocytes. Therefore, a possible reason for the finding of no change in IL- 6 level in the transdermal ET group is that the production of IL- 6 was induced in various tissues in response to estrogen.

It has been shown that $\mathrm{E}_{2}$ inhibited the production of MCP-1 protein in human coronary artery smooth muscle cells (32), and that $E_{2}$ treatment reduced mRNA expression of $M c p-1$ in injured arteries of ovariectomized rats (33). In the present study, only transdermal ET significantly decreased MCP-1 level. It has been reported that the expression of MCP-1 was enhanced in endothelial cells (34) and that MCP-1 level was significantly correlated with maximum 
intima-media thickness, which was associated with severity of atherosclerosis in coronary arteries (35). Transdermal ET may have a favorable effect on endothelial function due to reduction in MCP-1 level. Decrease in MCP-1 by estrogen might have been masked by first-pass hepatic metabolism in the oral ET group.

Serum MIP-1 $\beta$ level at 12 months was significantly decreased in the transdermal group, but tended to be increased in the oral ET group. It has been reported that MIP-1 $\beta$ was expressed in advanced atherosclerotic lesions. Therefore, transdermal ET may have a favorable effect on the development of atherosclerosis.

We demonstrated that CRP levels were not significantly different between the oral and transdermal ET groups, while oral ET but not transdermal ET has been shown to raise the level of CRP in postmenopausal women $(1,4,19,20)$. The differences in the changes in cytokines and inflammatory markers between the oral and transdermal ET groups may be due to differences in background characteristics of the subjects. The subjects in the present study were relatively young and their BMIs were relatively low compared to those in other studies. The small number of subjects and differences in the metabolism in the liver might also be relevant.

In the present study, we recruited postmenopausal women who had undergone hysterectomy in order to determine the effects of only ET. Progestogen is needed in order to prevent endometrial hyperplasia in women with an intact uterus. Estrogen-progestogen therapy may have different effects on cytokines and chemokines in postmenopausal women. Therefore, further study for assessment of cytokines and chemokines in women receiving estrogen-progestogen therapy is needed.

There are several limitations to this study. First, we compared the levels of cytokines and chemokines and the levels of inflammatory markers between women receiving oral $\mathrm{CEE}$ and women receiving transdermal $\mathrm{E}_{2}$ at conventional doses, but different changes in circulating cytokines and chemokines may be observed with different doses of estrogen. Secondly, CEE contains at least ten natural estrogens, including equine, estrone, and $E_{2}$, while transdermal $E_{2}$ contains only $E_{2}$ (36). Further studies are needed.

Taking into consideration our results regarding cytokines and chemokines in women receiving oral ET and women receiving transdermal ET, estrogen administered transdermally may have favorable effects on vascular inflammation in relationship to changes in cytokines and chemokines in postmenopausal women.

In conclusion, transdermal ET reduces circulating levels of IL-8, MCP-1, and MIP-1 $\beta$, while both oral ET and transdermal ET reduce the circulating level of IL-7. A direct comparison of the effects of oral administration and transdermal administration is, however, not possible, given the differences in the two preparations as discussed above.

\section{Declaration of interest}

The authors declare that there is no conflict of interest that would prejudice the impartiality of this scientific work.

\section{Funding}

This work did not receive any specific grant from any funding agency in the public, commercial, or not-for profit sector.

\section{References}

1 Shifren JL, Rifai N, Desindes S, McIlwain M, Doros G \& Mazer NA. A comparison of the short-term effects of oral conjugated equine estrogens vs. transdermal estradiol on C-reactive protein, other serum markers of inflammation and other hepatic proteins in naturally menopausal women. Journal of Clinical Endocrinology and Metabolism 200893 1702-1710.

2 Eilertsen AL, Hoibraaten E, Os I, Andersen TO, Sandvik L \& Sandset PM. The effect of oral and transdermal hormone replacement therapy on C-reactive protein levels and other inflammatory markers in women with high risk of thrombosis. Maturitas 200552 111-118.

3 Sumino H, Ichikawa S, Kasama S, Takahashi T, Kumakura H, Takayama Y, Kanda T \& Kurabayashi M. Different effects of oral conjugated estrogen and transdermal estradiol on arterial stiffness and vascular inflammatory markers in postmenopausal women. Atherosclerosis 2006189 436-442.

4 Vongpatanasin W, Tuncel M, Wang Z, Arbique D, Mehrad B \& Jialal I. Differential effects of oral versus transdermal estrogen replacement therapy on C-reactive protein in postmenopausal women. Journal of the American College of Cardiology 200341 1358-1363.

5 Ho JY, Chen M, Sheu WH, Yi Y, Tsai AC, Guu H \& Ho ES. Differential effects of oral conjugated equine estrogen and transdermal estrogen on atherosclerotic vascular disease risk markers and endothelial function in healthy postmenopausal women. Human Reproduction 200621 2715-2720.

6 Wakatsuki A, Ikenoue N, Shinohara K, Watanabe K \& Fukaya T. Effect of lower dosage of oral conjugated equine estrogen on inflammatory markers and endothelial function in healthy postmenopausal women. Arteriosclerosis, Thrombosis, and Vascular Biology 200424 571-576.

7 Brooks-Asplund EM, Tupper CE, Daun JM, Kenney WL \& Cannon JG. Hormonal modulation of interleukin-6, tumor necrosis factor and associated receptor secretion in postmenopausal women. Cytokine 200219 193-200.

8 Lakoski SG, Liu Y, Brosnihan KB \& Herrington DM. Interleukin-10 concentration and coronary heart disease (CHD) event risk in the estrogen replacement and atherosclerosis (ERA) study. Atherosclerosis $2008197443-447$.

9 Ariel A, Hershkoviz R, Cahalon L, Williams DE, Akiyama SK, Yamada KM, Chen C, Alon R, Lapidot T \& Lider O. Induction of $\mathrm{T}$ cell adhesion to extracellular matrix or endothelial cell ligands by soluble or matrix-bound interleukin-7. European Journal of Immunology 199727 2562-2570.

10 Denis V, Dupuis P, Bizouarne N, Sampaio S, Hong L, Lebret M, Monsigny $M$, Nakache $M$ \& Kieda C. Selective induction of peripheral lymph nodes and Peyer's patch cell-conditioned media. Journal of Leukocyte Biology 199660 744-752.

11 Dus D, Krawczenko A, Zalecki P, Paprocka M, Wiedlocha A, Goupille C \& Kieda C. IL-7 receptor is present on human microvascular endothelial cells. Immunology Letters $2003 \mathbf{6 8}$ 163-168.

12 Kim CS, Park HS, Kawada T, Kim JH, Lim D, Hubbard NE, Kwon BS, Erickson KL \& Yu R. Circulating levels of MCP-1 and IL-8 
are elevated in human obese subjects and associated with obesityrelated parameters. International Journal of Obesity $2006 \mathbf{3 0}$ 1347-1355.

13 Reape TJ \& Groot PH. Chemokines and atherosclerosis. Atherosclerosis 1999147 213-225.

14 Sunday L, Tran MM, Krause DN \& Duckles SP. Estrogen and progestogens differentially modulate vascular proinflammatory factors. American Journal of Physiology. Endocrinology and Metabolism 2006291 E261-E267.

15 Yeboah J, Reboussin DM, Waters D, Kowalchuk G \& Herrington DM. Effects of estrogen replacement with and without medroxyprogesterone acetate on brachial flow-mediated vasodilator responses in postmenopausal women with coronary artery disease. American Heart Journal 2007153 439-444.

16 Ligthart GJ, Corberand JX, Fournier C, Galanaud P, Hijmans W, Kennis B, Muller-Hermelink HK \& Steinmann GG. Admission criteria for immunogerontological studies in man: the SENIEUR protocol. Mechanisms of Ageing and Development 198428 47-55.

17 Yasui T, Maegawa M, Tomita J, Miyatani Y, Yamada M, Uemura H, Matsuzaki T, Kuwahara A, Kamada M, Tsuchiya N, Yuzurihara M, Takeda S \& Irahara M. Changes in serum cytokine concentrations during the menopausal transition. Maturitas 200756 396-403.

18 Yasui T, Uemura $\mathrm{H}$, Hyodo $\mathrm{S}$, Yamada $\mathrm{M}$, Yamamoto $\mathrm{S}$, Maegawa M, Tsuchiya N, Noguchi M, Yuzurihara M, Kase Y \& Irahara M. Raloxifene reduced circulating levels of interleukin-7 and monocyte chemoattractant protein-1 in postmenopausal women. Atherosclerosis $2009 \mathbf{2 0 4} 471-475$.

19 Vehkavaara S, Silveira A, Hakala-Ala-Pierila T, Virkamaki A, Hovatta O, Hamsten A, Taskinen MR \& Yki-Jarvinen H. Effects of oral and transdermal estrogen replacement therapy on markers of coagulation, fibrinolysis, inflammation and serum lipids and lipoproteins in postmenopausal women. Thrombosis and Haemostasis 200185 619-625.

20 Herrington DM, Brosnihan KB, Pusser BE, Seely EW, Ridker PM, Rifai N \& MacLean DB. Differential effects of $E$ and droloxifene on C-reactive protein and other markers of inflammation in healthy postmenopausal women. Journal of Clinical Endocrinology and Metabolism $2001864216-4222$.

21 Yasui T, Uemura H, Tomita J, Miyatani Y, Yamada M, Kuwahara A, Matsuzaki T, Maegawa M, Tsuchiya N, Yuzurihara M, Takeda S \& Irahara M. Association of interleukin-8 with hot flashes in premenopausal, perimenopausal, and postmenopausal women and bilateral oophorectomized women. Journal of Clinical Endocrinology and Metabolism 200691 4805-4808.

22 Noguchi M, Yuzurihara M, Kase Y, Yasui T \& Irahara M. Involvement of cytokine-induced neutrophil chemoattractant in hypothalamic thermoregulation of luteinizing hormone-releasing hormone. Endocrinology 2008149 2899-2906.

23 Masumoto T, Ohkubo K, Yamamoto K, Ninomiya T, Abe M, Akbar SM, Michitaka K, Horiike N \& Onji M. Serum IL-8 levels and localization of IL-8 in liver from patients with chronic viral hepatitis. Hepatogastroenterology 199845 1630-1634.

24 Isse K, Harada K \& Nakanuma Y. IL-8 expression by biliary epithelial cells is associated with neutrophilic infiltration and reactive bile ductules. Liver International 200727 672-680.
25 Yang QW, Mou L, Lv FL, Wang JZ, Wang L, Zhou HJ \& Gao D. Role of Toll-like receptor 4/NF-kappaB pathway in monocyte-endothelial adhesion induced by low shear stress and ox-LDL. Biorheology 200542 225-236.

26 Bruun JM, Lihn AS, Madan AK, Pedersen SB, Schiott KM, Fain JN \& Richelsen B. Higher production of IL-8 in visceral vs. subcutaneous adipose tissue. Implication of nonadipose cells in adipose tissue. American Journal of Physiology. Endocrinology and Metabolism 2004286 E8-E13.

27 Blum A, Schenke WH, Hathaway L, Mincemoyer R, Csako G, Waclawiw MA \& Cannon RO III. Effects of estrogen and the selective estrogen receptor modulator raloxifene on markers of inflammation in postmenopausal women. American Journal of Cardiology $200086892-895$.

28 Ucan HB, Kaplan M, Salman B, Yilmaz U, Mentes BB \& Aybay C. Effect of oophorectomy and exogenous estrogen replacement on liver injury in experimental obstructive jaundice. World Journal of Gastroenterology 200814 2818-2824.

29 Saucedo R, Rico G, Basurto L, Ochoa R \& Zarate A. Transdermal estradiol in menopausal women depresses interleukin-6 without affecting other markers of immune response. Gynecologic and Obstetric Investigation 200253 114-117.

30 Berg G, Ekerfelt C, Hammar M, Lindgren R, Matthiesen L \& Ernerudh J. Cytokine changes in postmenopausal women treated with estrogens: a placebo-controlled study. American Journal of Reproductive Immunology 200248 63-69.

31 Judd AM, Call GB, Barney M, McIlmoil CJ, Balls AG, Adams A \& Oliveira GK. Possible function of IL- 6 and TNF as intraadrenal factors in the regulation of adrenal steroid secretion. Annals of the New York Academy of Sciences 2000917 628-637.

32 Seli E, Pehlivan T, Selam B, Garcia-Velasco JA \& Arici A. Estradiol down-regulates MCP-1 expression in human coronary artery endothelial cells. Fertility and Sterility 200277 542-547.

33 Miller AP, Feng W, Xing D, Weathington NM, Blalock E, Chen YF \& Oparil S. Estrogen modulates inflammatory mediator expression and neutrophil chemotaxis in injured arteries. Circulation 2004 110 1664-1669.

34 Yla-Herttuala S, Lipton BA, Rosenfeld ME, Sarkioja T, Yoshimura T, Leonard EJ, Witztum JL \& Steinberg D. Expression of monocyte chemoattractant protein 1 in macrophage-rich areas of human and rabbit atherosclerotic lesions. PNAS $1991 \mathbf{8 8}$ 5252-5256.

35 Stork S, Baumann K, von Schacky C \& Angerer P. The effect of $17 \beta$-estradiol on MCP-1 serum levels in postmenopausal women. Cardiovascular Research 200253 642-649.

36 Bhavnani BR. Pharmacokinetics and pharmacodynamics of conjugated equine estrogens: chemistry and metabolism. Proceedings of the Society for Experimental Biology and Medicine 1998217 $6-16$.

Received 14 May 2009

Accepted 15 May 2009 